\title{
How ionic liquids can help to stabilize native proteins
}

\author{
Hermann Weingärtner, ${ }^{*} a$ Chiara Cabrele ${ }^{b}$ and Christian Herrmann ${ }^{c}$ \\ Received 15th June 2011, Accepted 26th October 2011 \\ DOI: $10.1039 / \mathrm{c} 1 \mathrm{cp} 21947 \mathrm{~b}$ \\ The native state of a globular protein is essential for its biocatalytic function, but is marginally \\ stable against unfolding. While unfolding equilibria are often reversible, folding intermediates and \\ misfolds can promote irreversible protein aggregation into amorphous precipitates or highly \\ ordered amyloid states. Addition of ionic liquids - low-melting organic salts-offers intriguing \\ prospects for stabilizing native proteins and their enzymatic function against these deactivating \\ reaction channels. The huge number of cations and anions that form ionic liquids allows \\ fine-tuning of their solvent properties, which offers robust and efficient strategies for solvent \\ optimization. Going beyond case-by-case studies, this article aims at discussing principles for \\ a rational design of ionic liquid-based formulations in protein chemistry and biocatalysis.
}

\section{Introduction}

Proteins fold to a native structure, which is essential for their enzymatic function. Despite their molecular diversity, native proteins share the common trait of being only marginally stable. ${ }^{1}$ The Gibbs energy of unfolding from the native state $\mathrm{N}$ to an ensemble of unfolded states $\mathrm{U}, \Delta_{\mathrm{unf}} G=G_{\mathrm{U}}-G_{\mathrm{N}}$, is typically less than $60 \mathrm{~kJ}$ per mol of protein, ${ }^{2}$ which roughly corresponds

\footnotetext{
${ }^{a}$ Department of Physical Chemistry II, Faculty of Chemistry and Biochemistry, Ruhr-University, D-44780 Bochum, Germany. E-mail: hermann.weingaertner@rub.de

${ }^{b}$ Department of Organic Chemistry I, Faculty of Chemistry and Biochemistry, Ruhr-University, D-44780 Bochum, Germany Department of Physical Chemistry I, Faculty of Chemistry and Biochemistry, Ruhr-University, D-44780 Bochum, Germany
}

to the energy of three hydrogen bonds. For comparison, hen egg white lysozyme - an often used protein - contains about two hundred intrapeptide H-bonds.

The low stability reflects a subtle balance of molecular forces. Stabilization primarily results from hydrophobic forces and H-bonds, while destabilization is mainly founded in an entropic force due to the loss of configurational freedom of the folded chain. ${ }^{1}$ It needs only a moderate environmental stress, such as an increase in temperature ${ }^{2}$ or pressure $^{3}$ or the addition of a co-solvent, ${ }^{4,5}$ to upset this balance. For example, the melting temperatures $T_{\mathrm{m}}$ of simple proteins, defined as the temperature at which $50 \%$ of the protein molecules are unfolded, rarely exceed $80{ }^{\circ} \mathrm{C}$.

For some proteins unfolding can be described by a reversible two-state equilibrium $\mathrm{N} \leftrightarrow \mathrm{U},{ }^{6}$ but usually unfolding proceeds

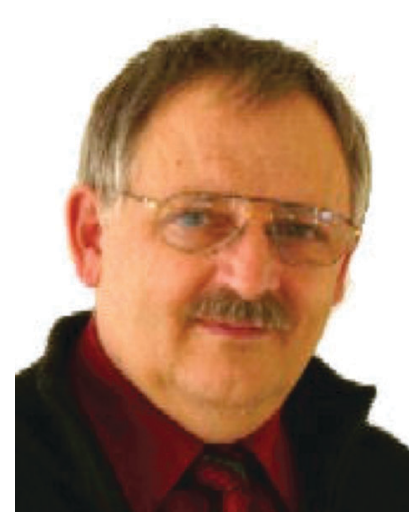

Hermann Weingärtner
Hermann Weingärtner received his doctorate in 1976 for work on nuclear magnetic resonance in electrolyte solutions, carried out in the group of H. G. Hertz at the University of Karlsruhe. After several research fellowships, among others at the Australian National University of Canberra, he was appointed in 1995 to a professorship for Physical Chemistry at the Ruhr-University of Bochum. His major scientific activities are in the field of electrolyte solutions and ionic liquids and their effects on biomolecular processes.

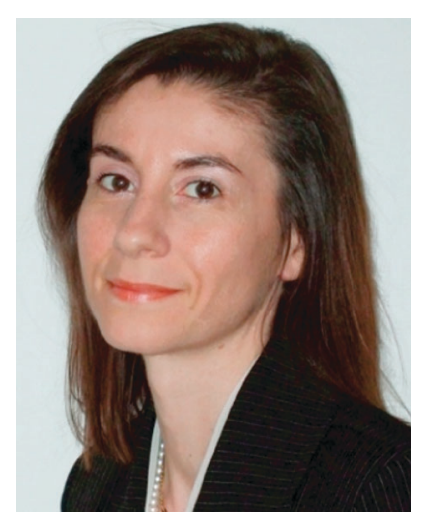

Chiara Cabrele

Chiara Cabrele received her MSc in Chemistry from the University of Padova (1994) and her PhD in Chemistry from ETH Zurich (1999). After a EU-Marie-Curie Postdoctoral Fellowship at the Max Planck Institute for Biochemistry in MartinsriedMunich with Prof. L. Moroder, she moved to the University of Regensburg (Germany) in 2002, where she started independent research funded by the Emmy-Noether Grant of the German Science Foundation (DFG). In 2008 she moved to the Ruhr-University Bochum as a Professor for Organic Chemistry. Her scientific interests are in peptide and protein chemistry and function. 
via partially unfolded intermediates. Such intermediates and misfolds due to improper refolding form nuclei for irreversible non-native protein aggregation. ${ }^{7-9}$ This pathway is particularly critical because a moderate increase in temperature can readily perturb the native fold to create aggregation-competent species. Because partially unfolded molecules will also be present in the native ensemble, aggregation limits the stability of proteins even under optimum conditions below $T_{\mathrm{m}}$.

In a first approach it is convenient to grasp the early steps of these aggregation phenomena in terms of the well-known Lumry-Eyring scheme ${ }^{7}$

$$
\mathrm{N} \leftrightarrow \mathrm{T} \rightarrow \mathrm{A}_{\mathrm{m}}
$$

where the native protein $\mathrm{N}$ reversibly unfolds to a transient species $T$, which irreversibly aggregates to small multimers $A_{m}$. These multimers can act as nuclei for further aggregation.

In vivo, protein aggregation is a key factor in pathological diseases, such as Alzheimer's, Huntington's or CreutzfeldtJacob disease. ${ }^{10}$ In vitro, it hinders biocatalytic formulations in laboratory and large-scale processes. ${ }^{8}$ In the pharmaceutical field it limits the shelf life of protein-based drugs. ${ }^{8,11}$ Aggregation is also crucial for the production of recombinant proteins in bacterial systems, where proteins are formed in intracellular "inclusion bodies". 12 After cell disruption, these have to be solubilized and refolded to the native structure, which opens channels for unproductive aggregation.

To make enzymes more tolerant against environmental stress, one can modify their state, for example by site-directed mutagenesis ${ }^{13}$ or by adhesion-induced conformational changes on solid supports. ${ }^{14}$ Alternatively, one can optimize the solvent environment. ${ }^{4,15}$ In the latter case low-melting organic salts, called ionic liquids (ILs), ${ }^{17-20}$ are at the forefront of the current research. $^{21-24}$

ILs possess unique properties, such as a very low vapour pressure and high thermal stability. The main advantage is, however, founded in their enormous diversity. Estimates show that $\sim 10^{6}$ combinations of known cations and anions can form ILs. ${ }^{19}$ The resulting possibility to systematically manipulate

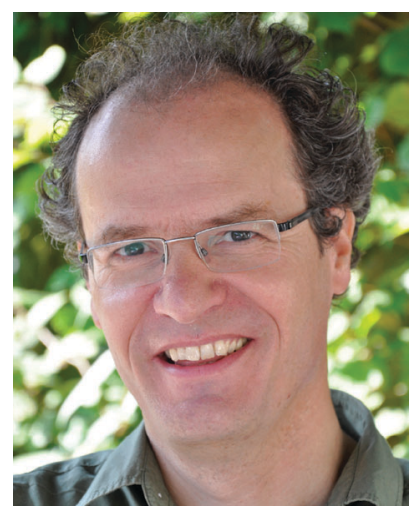

Christian Herrmann received his Chemistry degree (1988) as well as the doctoral degree (1991) in the group of $W$. Knoche at the University Bielefeld (Germany). After a postdoctoral stay until 1993 with Tom Barman and Franck Travers at INSERM/CNRS in Montpellier (France) he worked with Alfred Wittinghofer at the Max Planck Institute for Molecular Physiology in Dortmund (Germany). Since 2003 he is Professor for Physical Chemistry at Ruhr University of Christian Herrmann

Bochum (Germany). His research interests concern properties of proteins acting in cellular signal transduction chains, and the influence of small molecules, co-solvents and macromolecular compounds on these properties. their solvent properties can revolutionize chemical ${ }^{17-19}$ and biochemical $^{2-24}$ methodologies. In biochemical applications the power of ILs is largely increased by the possibility to design biocompatibility into their ions. ${ }^{25,26}$

Among a plethora of biochemical applications of ILs, ${ }^{21-24}$ enhancements of the thermal and functional stability of proteins ${ }^{21-24,27-33}$ open intriguing prospects for steering biotransformations. It is also possible to use ILs for destabilizing proteins systematically. ${ }^{34}$ As a generic feature, these effects are non-specific with regard to the protein and should be distinguished from "chemical" effects, in which ions act as enzymespecific substrates or co-substrates, although the borderline is somewhat indistinct.

How ILs affect the stability of proteins depends on intrinsic properties of the solutions, such as buffer and $\mathrm{pH}$, as well as on external processing conditions. Solvent optimization is therefore a multivariate problem. Moreover, one should distinguish between the stability of the native fold and the stability of the enzymatic function. The former is a thermodynamic property, while the latter describes the ability of a protein to retain its enzymatic activity over time. A careless blend of these properties will obscure the understanding of protein stabilization by ILs.

This article pinpoints progress made in characterizing and understanding these phenomena. First, we consider general scenarios of protein folding, protein aggregation and salt effects on these phenomena. We then describe some solvent properties of ILs which are relevant for biomolecular applications. Based on this background and on the general knowledge about co-solvent effects by non-ionic additives ${ }^{8,15}$ and simple salts ${ }^{16,35,36}$ we discuss the use of ILs for steering processes in protein solutions. Examples are mainly taken from our own work. For other issues and opinions surrounding biocatalysis in ILs we refer to reviews in the literature. ${ }^{21-24}$

\section{Folding and aggregation: the general scenario}

Proteins can adopt a variety of structures with many reaction channels between them. Fig. 1 pinpoints the most important pathways, adapting a scheme presented by Vendruscolo and Dobson. ${ }^{10}$ The scenario in Fig. 1 is by no means exhaustive. For example, it does not include chemical degradation, such as deamidation, oxidation or disulfide bond shuffling.

The native protein can undergo crystallization, native oligomerization or unfolding (Fig. 1). Partially unfolded intermediates and misfolds expose hydrophobic residues, which in the native fold are buried in its interior. The resulting increase in hydrophobic interactions drives non-native protein aggregation, ${ }^{8}$ which can lead to disordered or ordered states. Following ideas by Wolynes, Onuchic and Thirumalai, ${ }^{37}$ these processes can be described by an energy landscape, which is funneled to the folded state. ${ }^{9,10,38}$ In particular, proteins can form oligomers, which in a multistep process ${ }^{39}$ act as nuclei for highly ordered structures called amyloid fibrils. ${ }^{40}$ In spite of different amino-acid sequences in proteins, these fibrils have similar structures, with intermolecular $\beta$-sheets as a main structural motif., 9,40

The deposit of cytotoxic oligomers and amyloids in tissues can result in cell-degenerative diseases, such as Alzheimer's, Huntington's or Creutzfeldt-Jacob disease. ${ }^{10,41}$ For a long time 


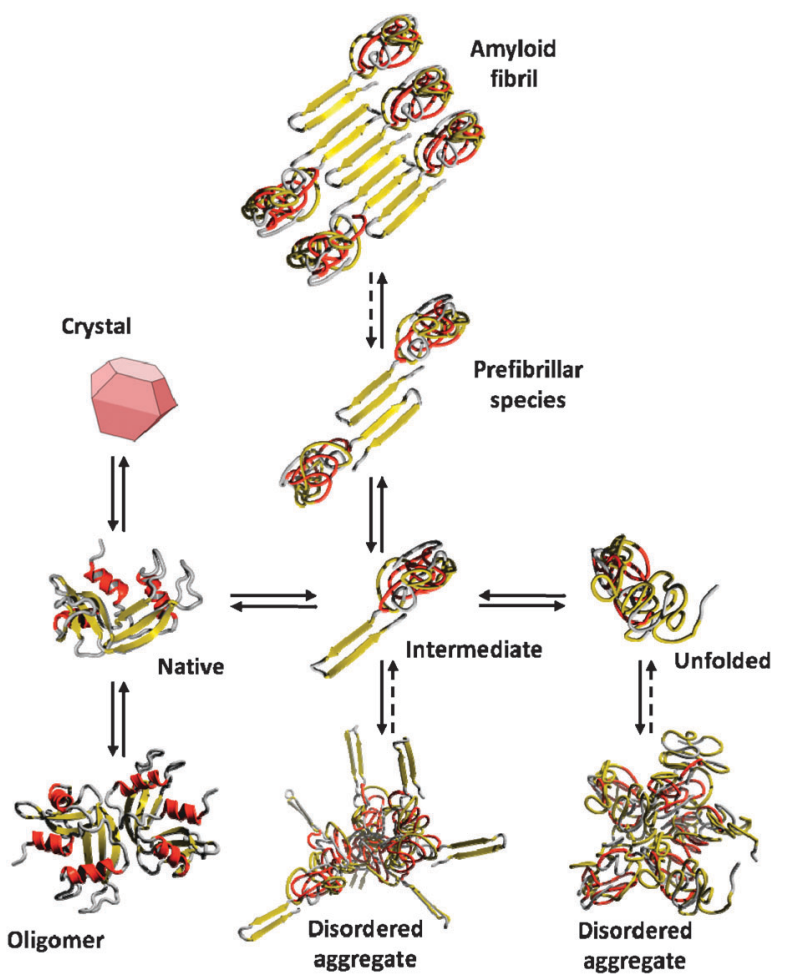

Fig. 1 Different states of proteins and possible reaction pathways between these states, as adapted from ref. 10. The states and pathways shown are not exhaustive.

amyloid fibrils were considered as a curiosity of pathological diseases. At least at high protein concentrations, they are now recognized as a highly stable, generic state, although the propensity to form this state differs for each protein..$^{9,10}$

Solvent modification can affect all steps in Fig. 1, both with regard to the thermodynamic stability of the species and kinetic barriers of the reactions. ${ }^{4,8,15,16}$ Solvent modification can stabilize or destabilize the native fold, ${ }^{27-34}$ enhance refolding, ${ }^{42,43}$ optimize protein crystallization, ${ }^{44}$ disrupt aggregates, ${ }^{32}$ or steer the formation of intermediates. ${ }^{32,45,46}$ The literature contains many useful, but more-or-less empirical guide lines for solvent optimization. ${ }^{4,8,15,16}$ Rational strategies for solvent optimization require their molecular understanding.

\section{Simple inorganic salts as additives}

Because natural media are usually crowded by ions, the role of inorganic salts in biomolecular processes has been studied for a long time. At low concentrations salt effects on proteins are dominated by electrostatic forces between ions and the charged protein. At concentrations above $\sim 0.05 \mathrm{M}$ ion-specific effects become detectable, which largely increase with increasing salt concentration. ${ }^{35,36}$ Applications mostly concern the regime of high salt concentrations, above $0.5 \mathrm{M}$. An illustrative example is protein solubility. At low salt concentrations non-specific electrostatic forces generally enhance their solubility. At high salt concentrations the addition of salts can solubilize ("salt in") or precipitate ("salt out") proteins in a highly ion-specific manner. ${ }^{35}$

The ion-specificity of biomolecular phenomena was recognized as early as in 1888 by Franz Hofmeister, ${ }^{47}$ who observed that the salt-induced precipitation of hen egg white proteins obeys an anion series, now known as Hofmeister series. In the same way, one can construct a cation series. ${ }^{35}$

Hofmeister effects can show up in many guises and in systems of very different complexity. In protein chemistry these effects concern, among others, properties, such as the thermal and functional stability of proteins ${ }^{35,36}$ and protein crystallization. ${ }^{48}$ Essentially the same ion series are observed in numerous other systems of largely different complexity. ${ }^{35}$ Illustrative examples are solubilities of nonpolar gases in water, ${ }^{49}$ surface tensions of solutions, ${ }^{50}$ ion binding to micelles, ${ }^{51}$ or even bacterial growth. ${ }^{52}$

Ranking the anions according to their protein-stabilizing efficiency, a widely quoted excerpt of the Hofmeister series reads $^{35,36}$

$\left[\mathrm{SO}_{4}\right]^{2-}>[\mathrm{dhp}]^{-}>[\mathrm{ac}]^{-}>\mathrm{F}^{-}>\mathrm{Cl}^{-} \|>\mathrm{Br}^{-}>\mathrm{I}^{-}>[\mathrm{SCN}]^{-}$

The double bar $(\|)$ indicates the crossover from stabilizing to destabilizing behaviour. Abbreviations for complex anions are defined in Table 1. We note that there are cases, in which the Hofmeister anion series is reversed. ${ }^{53}$ The latter examples are little understood, ${ }^{54}$ and are not considered here.

By the same token, one can construct a cation series. An illustrative excerpt is ${ }^{35}$

$$
\mathrm{Cs}^{+}>\mathrm{K}^{+}>\mathrm{Na}^{+} \|>\mathrm{Li}^{+}>\mathrm{Mg}^{2+}>\mathrm{Al}^{3+} \text {. }
$$

The following features of these series may be pinpointed:

- The cation and anion series do not only rank the ions, but also define the direction of efficiency. For example, electrostatic and ion-specific effects of halide ions obey the same ion sequence, but the efficiency varies in opposite directions.

- For inorganic salts, anion variation is more efficient than cation variation. This dominance of anions was noted by Hofmeister. ${ }^{47}$ Some authors, explicitly or implicitly, associate Hofmeister effects only with anions. ${ }^{36}$

- Highly charged and/or small anions stabilize the native conformation. Large monovalent anions are destabilizing agents. Cations obey opposite correlations with charge and size. ${ }^{35}$

- Compared to many nonionic additives, inorganic salts exert only moderate effects. ${ }^{16,35}$

Table 1 Abbreviations for complex ions of ILs

\begin{tabular}{ll}
\hline$\left[\mathrm{C}_{2} \mathrm{mim}\right]^{+}$ & 1-Ethyl-3-methylimidazolium \\
{$\left[\mathrm{C}_{4} \mathrm{mim}\right]^{+}$} & 1-Butyl-3-methylimidazolium \\
{$\left[\mathrm{C}_{6} \mathrm{mim}\right]^{+}$} & 1-Hexyl-3-methylimidazolium \\
{$\left[\mathrm{C}_{4} \mathrm{mpyr}\right]^{+}$} & $N$-butyl- $N$-methylpyrrolidinium \\
{$\left[\mathrm{EtNH}_{3}\right]^{+}$} & Ethylammonium \\
{$\left[\mathrm{HOEtNH}_{3}\right]^{+}$} & (2-Hydroxyethyl)ammonium \\
{$[\mathrm{chol}]^{+}$} & Choline \\
{$\left[\mathrm{gua}^{+}\right.$} & Guanidinium \\
{$\left[\mathrm{R}_{4} \mathrm{~N}^{+}\right]^{+a}$} & Tetraalkylammonium \\
{$[\mathrm{dhp}]^{-}$} & Dihydrogenphosphate \\
{$[\mathrm{fo}]^{-}$} & Formate \\
{$[\mathrm{ac}]^{-}$} & Acetate \\
{$[\mathrm{lac}]^{-}$} & Lactate \\
{$[\mathrm{EtOSO}$} & \\
{$[\mathrm{dca}]^{-}$} & Ethylsulfate \\
{$[\mathrm{TfO}]^{-}$} & Dicyanamide \\
{$\left[\mathrm{Tf} \mathrm{N}_{2}\right]^{-}$} & Trifluoromethanesulfonate \\
${ }^{a} \mathrm{R}$ stands for methyl (Me), ethyl & Bis(trifluoromethanesulfonyl)imide $n$-propyl (Pr), $n$-butyl (Bu) and \\
$n$-hexyl (Hex), respectively. & \\
\hline
\end{tabular}




\section{Solvent properties of ionic liquids}

\section{Hydrogen-bonding characteristics}

The variability of ILs offers prospects for tailoring their properties to applications. ${ }^{17,18}$ Scheme 1 defines some ion families of interest. In analogy to a familiar classification of molecular solvents into aprotic and protic ones, one can distinguish between aprotic and protic ILs. The H-bond donating ability is usually a property of the cation. Anions act as H-bond acceptors. ${ }^{17,20}$

For a long time interest has mainly focused on aprotic ILs. Prototypical representatives are 1-alkyl-3-methylimidazolium (I), $N, N$-dialkylpyrrolidinium (II) and tetraalkylammonium (III) salts. ${ }^{17}$ Despite of their classification as aprotic species, some cations can form weak $\mathrm{H}$-bonds with proton-accepting anions. A well-known example is the acid hydrogen at carbon C-2 of the imidazolium ring. ${ }^{20,55}$

Protic ILs result from proton transfer in stoichiometric mixtures of a Brønsted acid with a Brønsted base $\mathrm{B}^{56}$

$$
\mathrm{B}+\mathrm{AH} \rightarrow \mathrm{BH}^{+}+\mathrm{A}^{-} \text {. }
$$

A well-known example is $\left[\mathrm{EtNH}_{3}\right]\left[\mathrm{NO}_{3}\right]$, which is the first purposely designed IL on record. ${ }^{57}\left[\mathrm{EtNH}_{3}\right]\left[\mathrm{NO}_{3}\right]$ is highly hydrophilic and forms a $\mathrm{H}$-bonded network, which in some regards resembles the $\mathrm{H}$-bonded network of water. ${ }^{58,59}$

The propensity to form $\mathrm{H}$-bonds can also be designed into cations by functionalization of side chains. An interesting family is founded in ions with $\mathrm{OH}$-terminated alkyl chains. Choline (V) is an important biocompatible ion of this type. ${ }^{60}$

\section{Solvent polarity}

Polarity is a widely used concept for assessing the solvation capability of a solvent. ${ }^{61}$ Because solute-solvent interactions result from a variety of intermolecular forces, chemists have an arsenal of polarity parameters for describing solvation.

Macroscopically, polarity is often described by the static dielectric constant $\varepsilon$ of the liquid. In modeling solvation, the knowledge of $\varepsilon$ is mandatory because many electrostatic theories treat the solvent as a dielectric continuum. In spite of

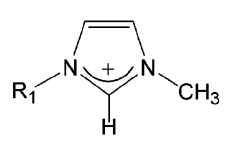

(I)

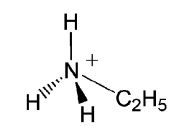

(IV)

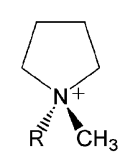

(II)

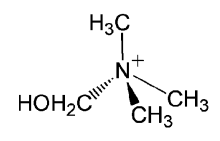

(V)

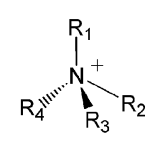

(III)<smiles>N=[N+](N)N</smiles>

(VI)<smiles>O=S(=O)([O-])C(F)(F)F</smiles>

(VII)<smiles>[13CH3]S(=O)(=O)[N-]S(=O)(=O)C(F)(F)F</smiles>

(VIII)

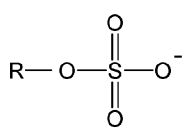

(IX)

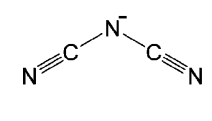

$(\mathbf{X})$
Scheme 1 Some typical ions of ionic liquids. (I) 1-Alkyl-3-methylimidazolium; (II) $N$-alkyl- $N$-methylpyrrolidinium; (III) tetraalkylammonium; (IV) ethylammonium; (V) choline; (VI) guanidinium; (VII) trifluoromethylsulfonate; (VIII) bis(trifluoromethylsulfonyl)imide (IX) alkylsulfate; (X) dicyanamide. their simplicity, continuum models form a useful starting point for describing solvation in ILs. ${ }^{62}$

For electrically conducting ILs it needs sophisticated methods of dielectric relaxation spectroscopy to determine $\varepsilon{ }^{63}$ Such experiments assign to most aprotic ILs fairly low dielectric constants, of the order of $\varepsilon=10-16$ at $25{ }^{\circ}$ C. ${ }^{63-65}$ Only ILs with some oxo-anions exhibit higher values, up to $\varepsilon \cong 35$. ${ }^{64}$ For comparison, water has $\varepsilon=78.3$. Addition of an aprotic IL will therefore decrease the dielectric constant of an aqueous protein solution. Protic ILs can show larger values, up to $\varepsilon \cong 85$ for $\left[\mathrm{HOEtNH}_{3}\right][\mathrm{lac}],{ }^{64,66}$ thus creating similar dielectric conditions as encountered in aqueous solutions.

Spectroscopic probes for assessing local interactions are often founded in UV/VIS absorption or fluorescence spectra of solvatochromic dyes. ${ }^{67-70}$ Although the results depend on the dye used, ${ }^{68}$ solvatochromic methods commonly assign to aprotic ILs polarities similar to those of acetonitrile or methanol, corresponding to dielectric constants of $\varepsilon \cong 25-40$. These values are markedly higher than the measured $\varepsilon$ values. Predictions of $\varepsilon$ from solvatochromic shifts, and vice versa, are therefore often off the mark, reflecting the difference between local and bulk solvent effects.

A sophisticated approach by Kamlet, Abboud and Taft ${ }^{69}$ separates the solvatochromic effect into contributions from the H-bond acidity of the cation, basicity of the anion, and dipolarity/polarizability of the ions. These contributions can be experimentally separated by using three or more dyes, which reflect these properties to a different extent. Lungwitz et al. ${ }^{68}$ and Hallett and Welton ${ }^{70}$ have recently discussed some key facets of this approach with regard to ILs.

It is suggestive to search for correlations between polarity parameters and the impact of ILs on the stability of enzymes. Some studies have yielded reasonable correlations, ${ }^{71,72}$ but in view of the multi-facetted molecular interactions it is fair to say that a general correlation cannot be expected.

\section{Hydrophobicity and water miscibility}

Hydrophobic interactions play a decisive role for the stability of the native fold. ${ }^{73}$ Like polarity, hydrophobicity of a solvent is not uniquely defined. A widely used phenomenological parameter is based on the "log $P$ scale", which describes the hydrophobicity of a species in terms of the logarithm of its partition coefficient $P$ between 1-octanol and water. There are many discussions ${ }^{22-24}$ on how this scale can be used to optimize enzyme stability. Despite of some success in specific cases, the $\log P$ scale does not provide a robust correlation with the thermal and enzymatic stability of proteins. ${ }^{23}$

The terms hydrophilic/hydrophobic ions are often used synonymously with water miscibility. Complete immiscibility with water does, however, not exist. "Immiscible" solvents can absorb notable amounts of water, which may play a key role for the stability of proteins in non-aqueous media. ${ }^{74}$

Limited miscibility of hydrophobic ILs with water has been frequently reported, but there lack systematic investigations of the liquid-liquid phase diagrams. There exist, however, extensive data for aqueous solutions of tetraalkylammonium salts, ${ }^{75}$ which, despite their high melting points, should reveal the general features of liquid-liquid phase equilibria of hydrophobic ILs. 


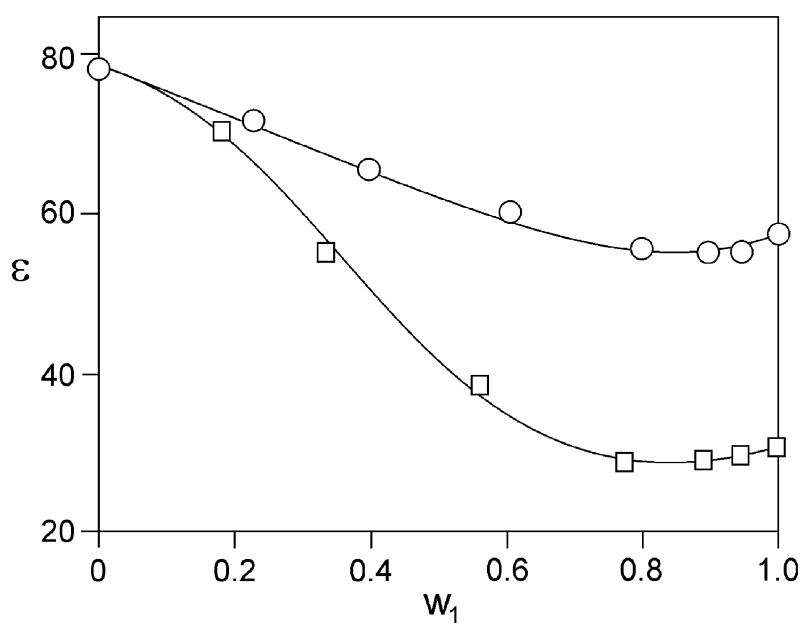

Fig. 2 Dependence of the static dielectric constant $\varepsilon$ of aqueous solutions of $\left[\mathrm{EtNH}_{3}\right][\mathrm{fo}]$ (squares) and $\left[\mathrm{HOEtNH}_{3}\right][\mathrm{fo}]$ (circles) on the weight fraction $w_{1}$ of the ILs at $25^{\circ} \mathrm{C}$. The estimated experimental uncertainty of $\varepsilon$ is $\pm 5 \%$.

Depending on both, the nature of the anion and cation, tetraalkylammonium salts show a wide range of behaviour from complete miscibility with water to broad immiscibility regions. ${ }^{75}$ In the latter situation the mixtures separate into a dilute electrolyte solution and a concentrated salt melt comprising little water.

The extension of the miscibility gaps can be characterized by the upper consolute temperature, $T_{\mathrm{c}}$, above which the salt becomes completely miscible. $T_{\mathrm{c}}$ largely increases with increasing length of the alkyl residues of the cations, pinpointing the decisive role of hydrophobic interactions. ${ }^{75}$ Some anions give rise to a similarly large increase in $T_{\mathrm{c}}$ as hydrophobic cations. The effects of the inorganic anions obey the Hofmeister series quoted above. $^{75}$

By contrast, many low-melting protic ILs are completely miscible with water. In these cases the solvent properties can be tuned from typical electrolyte solution behaviour to molten salt behaviour. As an example, Fig. 2 shows the composition dependence of the static dielectric constant $\varepsilon$ of solutions of $\left[\mathrm{EtNH}_{3}\right][\mathrm{fo}]$ and $\left[\mathrm{HOEtNH}_{3}\right][\mathrm{fo}] .{ }^{66}$ In the water-rich regime ILs decrease $\varepsilon$ in the same manner as simple inorganic salts. At high IL content the concentration dependence of $\varepsilon$ levels off. At $75 \mathrm{wt} \%$ of the IL the dielectric environment already closely corresponds to that in the neat IL.

\section{Microheterogeneity}

The charged ionic groups and nonpolar residues of cations and anions give rise to a nanoscale structural heterogeneity of ILs, which is not encountered in simple molecular solvents. ${ }^{76,77}$ The resulting hydrophilic and hydrophobic patches of the IL structure have intriguing consequences for solvation because they enable a dual solvent behaviour: an IL can incorporate a nonpolar solute in nonpolar domains, while hydrophilic domains solvate polar solutes. Thus, ILs can simultaneously dissolve species of very different nature. For example, carefully designed ILs can provide enzyme-compatible solvent systems, which dissolve large amounts of carbohydrates. ${ }^{78}$ Most molecular solvents do not dissolve carbohydrates to a notable extent.

\section{Biocompatibility}

ILs are often said to form "green" solvents. Their green behaviour is mainly founded in a practically vanishing vapour pressure, which largely facilitates their handling. ${ }^{18,19}$ Despite careful handling ILs may, however, find ways to contaminate the environment. Thus, the toxicity, bioaccumulation and biodegradation of ILs are key issues in all biomolecular applications. In biomedical applications biocompatibility is mandatory. ${ }^{25,26}$

With regard to biocompatibility, ILs cover a wide range from food-grade quality to highly toxic compounds. Strategies for designing biocompatible ILs can build upon ions that exist in nature. A prominent example is choline $(\mathbf{V})$, which is a micronutrient. ${ }^{25,26}$ Nature also offers biocompatible anions such as saccharinate, citrate or lactate. Elliott et al. ${ }^{25}$ have conjectured that in future the need for biocompatibility will shift interest from the ILs in use toward "greener" species.

\section{Proteins in ionic liquids at low hydration levels}

\section{Hydrophobic ionic liquids}

Much attention has focused on proteins in "neat" ILs with little or no water. The search for alternative solvents to water is suggestive because biocatalysis in aqueous solutions can be hampered by side reactions, hydrolysis or substrate solubility. Some enzymes tolerate weakly polar or nonpolar solvents, such as tetrahydrofurane or toluene, ${ }^{79}$ but loose activity in protic or polar solvents, such as dimethylsulfoxide or alcohols. The rationale is ${ }^{74}$ that in nonpolar solvents enzymes can retain a residual hydration shell, which stabilizes the native fold. Polar solvents drive denaturation by stripping off these residual water molecules.

In accordance with these ideas, some proteins were found to retain their enzymatic function in hydrophobic ILs up to temperatures well above $100{ }^{\circ} \mathrm{C},{ }^{27,28}$ reflecting previously unheard stabilizations. This high stability is surprising because the addition of hydrophobic ILs to aqueous protein solutions imposes strong denaturation. ${ }^{34}$ Results for lipases, which are often tolerant to non-aqueous solvents, confirm the picture deduced from molecular solvents. For example, candida antarctica lipase $B(\mathrm{CALB})$ maintained its activity in $\left[\mathrm{C}_{4} \mathrm{mim}\right]^{+}$based ILs, if the anion was weakly coordinating, such as $\left[\mathrm{PF}_{6}\right]^{-}$and $\left[\mathrm{BF}_{4}\right]^{-}$, but lost activity in the case of coordinating anions, such as $\mathrm{Cl}^{-}$or $[\mathrm{ac}]^{-80,81}$ In a small-angle neutron and light scattering study CALB in $\left[\mathrm{C}_{2} \mathrm{mim}\right][\mathrm{dca}]$ was found to form disk-like aggregates of about 150 molecules, while in water CALB did not aggregate at all. ${ }^{82}$

We have attempted to characterize the effect of a hydrophobic IL on the melting temperature $T_{\mathrm{m}}$ of a protein from dilute aqueous solutions to the neat IL. Unfolding gives rise to an endothermic contribution to the heat capacity of the solution, which can be probed by differential scanning calorimetry (DSC). Incomplete water miscibility prevented studies for many hydrophobic ILs, but water-miscible $\left[\mathrm{C}_{2} \mathrm{mim}\right][\mathrm{dca}]$ is sufficiently hydrophobic to provide the desired information. The experiments ${ }^{31,32,34}$ were conducted with the small protein ribonuclease A (RNase A), which is commonly used in studies of co-solvent effects on the thermal stability of proteins. ${ }^{4,5}$ At physiological conditions RNase A melts at $T_{\mathrm{m}}=63.5^{\circ} \mathrm{C}$. 


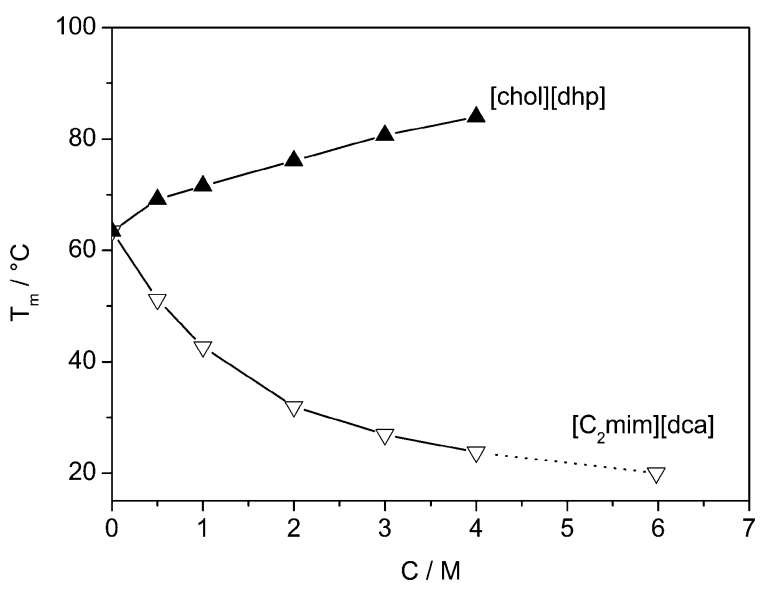

Fig. 3 Dependence of the melting temperature $T_{\mathrm{m}}$ of RNase A (protein concentration $0.36 \mathrm{mM}, 25 \mathrm{mM}$ phosphate buffer, $\mathrm{pH} 7.0$ ) on the concentration of added [chol][dhp] and $\left[\mathrm{C}_{2} \mathrm{mim}\right][\mathrm{dca}]$, respectively. The estimated experimental accuracy is $\pm 1{ }^{\circ} \mathrm{C}$. The dashed line shows a tentative extrapolation to neat $\left[\mathrm{C}_{2} \mathrm{mim}\right][\mathrm{dca}]$. Neat [chol][dhp] is solid under the experimental conditions.

Fig. 3 shows the effect of $\left[\mathrm{C}_{2} \mathrm{mim}\right][\mathrm{dca}]$ on $T_{\mathrm{m}}$ of this protein. ${ }^{31,32}$ Neat $\left[\mathrm{C}_{2} \mathrm{mim}\right][\mathrm{dca}]$ corresponds to a molar concentration of $C \cong 6 \mathrm{M}$, but a rapid decrease of the solubility of RNase A rendered meaningful DSC experiments above $C \cong 4 \mathrm{M}$ impossible. This decrease in protein solubility falls into the regime, where one expects a crossover of the solvent properties from electrolyte solution-like to molten salt-like behaviour.

The monotonous decrease of $T_{\mathrm{m}}$ in Fig. 3 classifies $\left[\mathrm{C}_{2} \mathrm{mim}\right][\mathrm{dca}]$ as a strong denaturant. Extrapolation to neat $\left[\mathrm{C}_{2} \mathrm{mim}\right][\mathrm{dca}]$ yields $T_{\mathrm{m}} \cong 15{ }^{\circ} \mathrm{C}$, which contradicts the high thermal stability of some proteins in hydrophobic ILs. ${ }^{23}$ As a consequence, there seems no obvious link between the behaviour of proteins in aqueous solutions and neat hydrophobic ILs.

There is now consensus ${ }^{28,30}$ that the molecular-level solubility of proteins in "neat" hydrophobic ILs is too low to account for the very high concentrations achieved in some experiments. Very likely, in most of these studies the enzymes were in finely dispersed states rather than being dissolved at the molecular level, as suggested by small-angle neutron and light scattering of CALB in $\left[\mathrm{C}_{2} \mathrm{mim}\right][\mathrm{dca}]$, which reveals aggregates of mesoscopic size. ${ }^{82}$ As an important consequence, the observed preservation of the enzymatic activities of some proteins in hydrophobic ILs at high temperatures seems to be founded in heterogeneous rather than homogeneous biocatalysis. ${ }^{28,30}$

\section{Hydrophilic ionic liquids}

The situation is different for hydrophilic ILs. Again, the low solubility of proteins in neat ILs is a major issue. Because hydrophilic ILs are completely miscible with water one can, however, assist protein solubility by adding water. Typically, $25 \mathrm{wt} \%$ water sufficiently increases protein solubility for meaningful applications, while retaining the environment of an IL at low hydration levels. Fujita et al ${ }^{28,30}$ reported that in this way solutions of [chol][dhp] preserve the secondary structure of cytochrome $c$ up to temperatures well above $100{ }^{\circ} \mathrm{C}$. At ambient conditions cytochrome $c$ remained active after 18 months of storage in hydrous [chol][dhp], which is a unique long-time stabilization. Similar stabilizations were reported for other proteins. ${ }^{27,29,31-33}$

Taken together, the following conclusions are apt:

- Neat hydrophobic ILs can accomodate large amounts of proteins and can stabilize them at temperatures well above their melting temperatures in buffered aqueous solutions. Because on the molecular level the solubility of proteins in hydrophobic ILs is low, these stabilizations probably refer to finely dispersed rather than truly dissolved states of the protein.

- By contrast, the water miscibility of hydrophilic ILs enables the design of concentrated hydrous ILs, which dissolve high concentrations of proteins, while retaining the major characteristics of neat ILs.

\section{Ion-specific effects on protein stability in aqueous environments: the Hofmeister series}

\section{Thermal stability of proteins}

Perhaps of larger relevance than the use of ILs as neat solvents for proteins is the possibility to manipulate the solvent properties of aqueous solutions. While factors such as the solvent polarity, H-bond characteristics or hydrophobicity of ILs have influence on protein stability, they do not seem to provide universal mechanisms. The ion-specificity of the observed effects directs attention to Hofmeister effects. ${ }^{22-24,34}$

Noting the rudimentary information provided by many caseby-case studies, we have recently systematized the Hofmeister series of ions of ILs using the melting temperature $T_{\mathrm{m}}$ of RNase A as a probe. ${ }^{31,32,34}$ Depending on the nature of the ions, both, stabilizing and destabilizing effects, can be generated. Fig. 3 shows as extreme cases effects exerted by [chol][dhp] and $\left[\mathrm{C}_{2} \mathrm{mim}\right][\mathrm{dca}]$, respectively. ${ }^{32}$ Based on data for a large variety of ILs the cation and anion series read ${ }^{32,34}$

$$
\begin{aligned}
& \mathrm{K}^{+}>\mathrm{Na}^{+}>\left[\mathrm{Me}_{4} \mathrm{~N}\right]^{+} \| \mathrm{Li}^{+}>[\mathrm{chol}]^{+}>\left[\mathrm{Et}_{4} \mathrm{~N}\right]^{+} \\
& \approx\left[\mathrm{C}_{2} \mathrm{mim}\right]^{+} \approx[\mathrm{gua}]^{+}>\left[\mathrm{C}_{4} \mathrm{mpyr}\right]^{+}>\left[\mathrm{C}_{4} \mathrm{mim}\right]^{+} \\
& \approx\left[\mathrm{Pr}_{4} \mathrm{~N}\right]^{+}>\left[\mathrm{C}_{6} \mathrm{mim}\right]^{+} \approx\left[\mathrm{Bu}_{4} \mathrm{~N}\right]^{+} \\
& {\left[\mathrm{SO}_{4}\right]^{2-}>[\mathrm{dhp}]^{-}>[\mathrm{ac}]^{-}>\mathrm{F}^{-}>\mathrm{Cl}^{-} \|[\mathrm{EtOSO}]^{-}>\left[\mathrm{BF}_{4}\right]^{-}} \\
& \approx \mathrm{Br}^{-}>[\mathrm{TfO}]^{-}>\mathrm{I}^{-}>[\mathrm{SCN}]^{-} \approx[\mathrm{dca}]^{-} \gg\left[\mathrm{Tf}_{2} \mathrm{~N}\right]^{-}
\end{aligned}
$$

where experimental uncertainty may allow for changes in the positions of neighbouring ions.

For assessing the benefits and limitations of these rankings it is worthwhile to note that the single-ion separation underlying the ion series is only meaningful at low salt concentrations, strictly speaking requiring extrapolation of the measured data towards infinite dilution of the ILs. ${ }^{5,34}$ By contrast, applications usually concern high concentrations of ILs, where mutual interference and co-operative effects of cations and anions may render ion rankings qualitative and may result in an interchange in the positions of the ions.

For illustration, we show in Fig. 4 results for the effect of [chol] $\mathrm{Cl}$ on the melting temperature of hen egg white lysozyme and $\alpha$-lactalbumin, respectively. ${ }^{83}$ In both cases $T_{\mathrm{m}}$ exhibits a shallow minimum, which at low concentrations classifies [chol $]^{+}$ as a slightly denaturating agent, consistent with the quoted Hofmeister series. At high concentrations the two proteins are, 


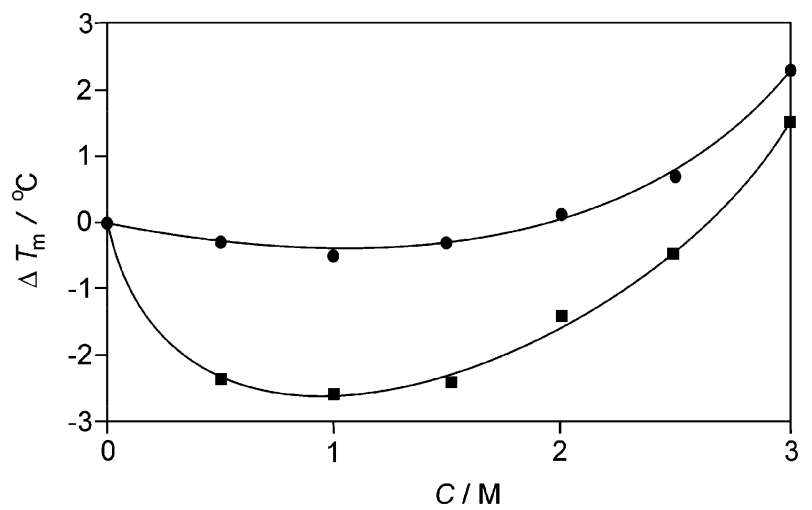

Fig. 4 Effect of [chol]Cl on the melting temperatures of hen egg white lysozyme (squares) and $\alpha$-lactalbumin (circles), both at $\mathrm{pH} 5.5$ and $10 \mathrm{mM}$ phosphate buffer. $\Delta T_{\mathrm{m}}$ is the difference to the melting temperatures of the IL-free solutions of lysozyme $\left(T_{\mathrm{m}}=76.4{ }^{\circ} \mathrm{C}\right)$ and $\alpha$-lactalbumin $\left(T_{\mathrm{m}}=64.3{ }^{\circ} \mathrm{C}\right)$. The estimated experimental accuracy of $\Delta T_{\mathrm{m}}$ is $\pm 0.5^{\circ} \mathrm{C}$.

however, markedly stabilized by [chol]Cl. In other words, [chol]Cl stabilizes these enzymes only above a certain threshold. So far, such concentration-dependent effects have found little attention and may be responsible for some confusing results in the literature.

Finally, we note that, except for $\left[\mathrm{Me}_{4} \mathrm{~N}\right]^{+}$, all organic cations of ILs considered so far are located at the destabilizing site of the Hofmeister series. Therefore, protein stabilization by ILs, such as [chol][dhp], mainly results from the combination of a slightly destabilizing cation such as $[\mathrm{chol}]^{+}$with a highly stabilizing anion. ${ }^{32}$ It would be, however, premature to conclude that, in seeking for stabilizing additives, organic cations will not offer advantages over simple inorganic ions. It is the combination with other intriguing properties of ILs, such as the high water miscibility or biocompatibility, which prospects beneficial applications.

\section{Functional stability of proteins}

With regard to biocatalysis, the stability of the enzymatic function of a protein is of central interest. In the literature results for the thermal stability are often assumed to be also valid for the functional stability and vice versa. ${ }^{21,24}$ While the preservation of the native fold is indeed a key factor for the enzymatic function, the enzymatic activity will also depend on other factors of the protein-substrate-solvent relationship, for example on competitive interactions of ions and substrates with the active site. The widely assumed correlation between salt effects on the thermal and functional stability is therefore by no means trivial.

We have recently addressed this issue ${ }^{84}$ by probing the effect of ILs on the enzymatic activity of yeast alcohol dehydrogenase (ADH), which transforms alcohols into aldehydes or ketones and vice versa. The enzymatic assay was based on the oxidation of ethanol with $\beta$-nicotinamide adenine dinucleotide as a co-substrate. ${ }^{85}$ The results enabled a detailed analysis of the enzyme kinetics in terms of the Michaelis-Menten reaction scheme $\mathrm{E}+\mathrm{S} \leftrightarrow \mathrm{ES} \rightarrow \mathrm{P}$ between the enzyme $\mathrm{E}$, substrate $\mathrm{S}$, enzyme/substrate complex ES and products $\mathrm{P} .{ }^{13}$ The analysis of the measured rate constants yields the apparent binding
Table 2 Effects of ILs on the enzymatic efficiency of the oxidation of ethanol catalyzed by yeast alcohol dehydrogenase ${ }^{a}$

\begin{tabular}{|c|c|c|c|}
\hline \multicolumn{2}{|l|}{ Anion dependence } & \multicolumn{2}{|c|}{ Cation dependence } \\
\hline & $\begin{array}{l}10^{-6} \cdot k_{\mathrm{cat}} / K_{\mathrm{M}} \\
\mathrm{s}^{-1} \mathrm{~mol}^{-1}\end{array}$ & & $\begin{array}{l}10^{-6} \cdot k_{\mathrm{cat}} / K_{\mathrm{M}} \\
\mathrm{s}^{-1} \mathrm{~mol}^{-1}\end{array}$ \\
\hline IL-free & 25.8 & $\mathrm{NaCl}$ & 35.7 \\
\hline$\left[\mathrm{C}_{2} \mathrm{mim}\right] \mathrm{Cl}$ & 17.4 & {$\left[\mathrm{Me}_{4} \mathrm{~N}\right][\mathrm{Cl}]$} & 32.8 \\
\hline$\left[\mathrm{C}_{2} \mathrm{mim}\right]\left[\mathrm{EtOSO}_{3}\right]$ & 3.62 & {$[\mathrm{chol}] \mathrm{Cl}$} & 26.3 \\
\hline$\left[\mathrm{C}_{2} \mathrm{mim}\right][\mathrm{TfO}]$ & 3.19 & IL-free & 25.8 \\
\hline$\left[\mathrm{C}_{2} \mathrm{mim}\right]\left[\mathrm{BF}_{4}\right]$ & 0.85 & {$[\mathrm{emim}] \mathrm{Cl}$} & 17.4 \\
\hline$\left[\mathrm{C}_{2} \mathrm{mim}\right][\mathrm{dca}]$ & 0.19 & [gua]Cl & 7.54 \\
\hline$\left[\mathrm{C}_{2} \mathrm{mim}\right][\mathrm{SCN}]$ & 0.027 & {$[\mathrm{bmim}] \mathrm{Cl}$} & 4.95 \\
\hline \multicolumn{4}{|c|}{$\begin{array}{l}{ }^{a} \text { Concentration of ADH: } 1.45 \times 10^{-7} \mathrm{M} ; \mathrm{pH}=9.0 \text {; IL concentration: } \\
0.5 \mathrm{M} \text {; temperature }(20 \pm 1)^{\circ} \mathrm{C} .\end{array}$} \\
\hline
\end{tabular}

constant $K_{\mathrm{M}}$ of the substrate (Michaelis constant), the number of product molecules per enzyme molecule per second called turnover number $k_{\text {cat }}$, and the enzymatic efficiency which is given by the ratio $k_{\text {cat }} / K_{\mathrm{M}}$. With regard to applications the enzymatic efficiency $k_{\text {cat }} / K_{\mathrm{M}}$ is by far the most important quantity. Table 2 summarizes the results for $k_{\text {cat }} / K_{\mathrm{M}}{ }^{85}$

Using $k_{\text {cat }} / K_{\mathrm{M}}$ as the ordering scheme both, the cation and anion dependences, agree with the above-mentioned Hofmeister series deduced from thermal stability data for RNase A. ${ }^{34}$ Moreover, the results in Table 2 reproduce the transition from stabilizing to destabilizing behaviour in these series. Thus, the results are "universal" with regard to both, the protein and the experimental property considered. By contrast, correlations of the apparent binding constant $K_{\mathrm{M}}$ and the turnover number $k_{\text {cat }}$ with the Hofmeister series (not shown here) are much less pronounced. Taken together, these results highlight the complexity of ion-specific effects, which on the one hand are predictable in the case of $k_{\mathrm{cat}} / K_{\mathrm{M}}$, and on the other hand appear to be unpredictable for $k_{\text {cat }}$ and $K_{\mathrm{M}}$.

\section{Structural studies}

Spectroscopy offers several methods for probing IL-induced changes of the protein structure, such as fluorescence, Fourier transform IR and circular dichroism (CD) spectroscopy. For example, circular dichroism (CD) spectroscopy - an important tool of biochemists - provides information on the protein's tertiary structure (in the near-UV between 250 and $320 \mathrm{~nm}$ ) and, more importantly, on the secondary structure (in the far-UV between 180 and $250 \mathrm{~nm}) .{ }^{86,87}$ In particular, far-UV CD spectra may allow to identify ion-induced structural changes of $\alpha$-helices, $\beta$-strands and disordered region, respectively.

To put this issue into perspective, we show in Fig. 5 results for the far-UV spectrum between 200 and $250 \mathrm{~nm}$ of phosphate buffered $\alpha$-chymotrypsin $\left(\alpha\right.$-CT) at $\mathrm{pH} 7.1 .^{88}$ The spectra were recorded at $20{ }^{\circ} \mathrm{C}$, where $(\alpha-\mathrm{CT})$ is markedly below its melting temperature of $T_{\mathrm{m}}=45{ }^{\circ} \mathrm{C} .{ }^{88}$ Below $200 \mathrm{~nm}$ the spectrum is obscured by strong absorption. The major features are a negative band near $203 \mathrm{~nm}$ and a less pronounced minimum at $229 \mathrm{~nm}$. The band near $203 \mathrm{~nm}$ is typical for proteins, which are rich in $\beta$-sheets and polyproline type II helices. Perhaps more interesting is the minimum at $229 \mathrm{~nm}$, which is characteristic of the active form of $\alpha$-CT because it is generated by the exciton coupling of two Trp residues separated by about $10 \AA$ in the proximity of the catalytic centre. 


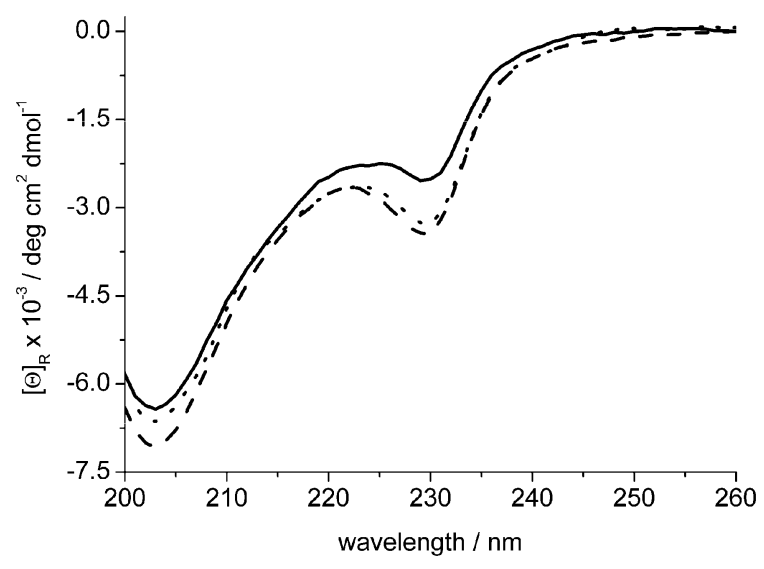

Fig. 5 Far-UV CD spectra of $\alpha$-CT $(10 \mu \mathrm{M}, 20 \mathrm{mM}$ phosphate buffer, $\mathrm{pH}$ 7.1) at $20{ }^{\circ} \mathrm{C}$ in the IL-free solution (solid line) and with $1.5 \mathrm{M}$ [chol][dhp] (dashed line) or 1.5 M [chol][Cl] (dotted line).

Stepwise addition of [chol][dhp] and [chol]Cl, respectively, yields spectral changes in both regions, which in Fig. 5 are illustrated by data for solutions containing $1.5 \mathrm{M}$ [chol][dhp] and $1.5 \mathrm{M}$ [chol] $\mathrm{Cl}$, respectively. Both, the regimes near 203 and $229 \mathrm{~nm}$, indicate stabilization of the protein conformation. In particular, these ILs favour the exciton coupling of the Trp residues near the active site. In the case of [chol][dhp] this structural change is accompanied by a pronounced increase of the melting temperature $T_{\mathrm{m}}$ from $45^{\circ} \mathrm{C}$ in the IL-free solution to $70{ }^{\circ} \mathrm{C}$ for $1.5 \mathrm{M}$ [chol][dhp]. A moderate increase of $T_{\mathrm{m}}$ to $58{ }^{\circ} \mathrm{C}$ was also observed by addition of $2 \mathrm{M}$ [chol] $\mathrm{Cl}$, confirming its stabilizing nature at high concentrations.

$\mathrm{CD}$ spectra can also shed light on the mechanism of thermal denaturation. Fig. 6 compares the far-UV CD spectrum of phosphate buffered, IL-free RNase A at $\mathrm{pH} 7.5$ with that of a solution containing $0.5 \mathrm{M}$ [chol] [dhp]..$^{32}$ In the native state at $10{ }^{\circ} \mathrm{C}$, far below the unfolding transition, the two spectra are very similar. The same is true for the spectra at $90{ }^{\circ} \mathrm{C}$, where thermal denaturation is complete. They behave, however, very differently in the transition regime $\left(60\right.$ and $\left.70{ }^{\circ} \mathrm{C}\right)$, where in the presence of [chol][dhp] the native structure is retained to higher temperatures than in the IL-free solution. Denaturation first affects the CD spectra at short wave length, where the
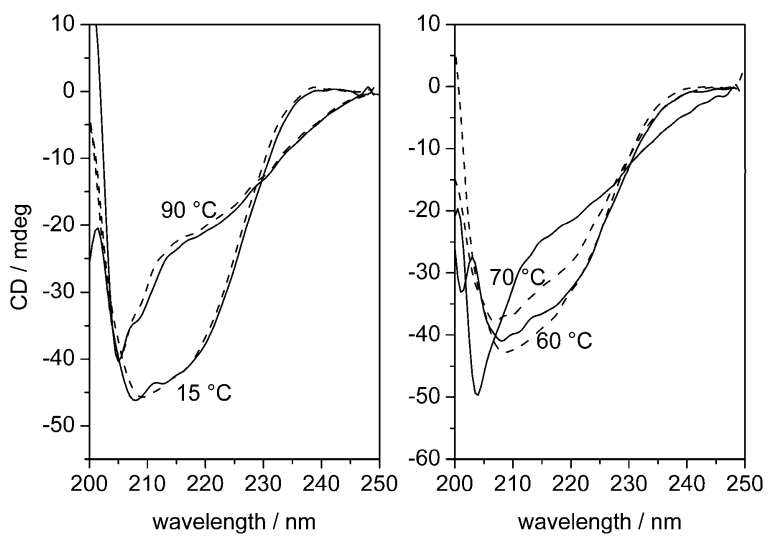

Fig. 6 Far-UV CD spectra of RNase A $(14 \mu \mathrm{M}, 20 \mathrm{mM}$ phosphate buffer, $100 \mathrm{mM} \mathrm{NaCl}, \mathrm{pH} 7.5$ ) in the IL free solution (solid line) and with $0.5 \mathrm{M}$ [chol][dhp] (dashed line) at different temperatures. spectrum mainly reflects contributions by $\beta$-strands. Thus, denaturation starts by perturbation of $\beta$-strands before changes in the $\alpha$-helical regions are observed.

\section{The molecular foundations of Hofmeister effects}

For discussing the molecular basis of the observed salt effects it is apt to first summarize some crucial experimental results:

- In contrast to the dominance of anion over cation effects in the case of inorganic salts ${ }^{35}$ cation variation in ILs results in similarly large effects as anion variation. This increased variability concerns only the destabilizing site of the Hofmeister series. Results for homologous cations show that the destabilizing tendency is closely related to the hydrophobicity of the organic cations.

- Most molecular anions of ILs do not form homologous series and their effects on proteins do not easily fit into a simple ordering scheme, except for the tentative conclusion that an increasing hydrophobicity of the anion increases the destabilizing tendency. The strongest stabilizing agents are oxo-anions such as $[\mathrm{dhp}]^{-}$.

The apparently generic ion rankings may mimic simplicity. However, more than 120 years after Hofmeister these ionspecific effects are still a particularly contentious issue, with outright contradiction between some interpretations. ${ }^{89-91}$

Hofmeister himself considered the "water withdrawing power of the salts" as an important effect. ${ }^{47}$ His interpretation comes surprisingly close to the widespread view that Hofmeister effects reflect ion-induced modifications of water's H-bonded network. ${ }^{35,92}$ Although this interpretation is no more considered to be a valid hypothesis, ${ }^{89-91}$ we briefly discuss the ideas behind this interpretation because, so far, practically all discussions on Hofmeister behaviour of ILs have resorted to this picture. ${ }^{21-24}$

The basic assumption is that the ions have different capacities to enhance or break the H-bonded bulk structure of water, ${ }^{92}$ which will affect protein hydration. ${ }^{35,93}$ Ions of high surface charge density (high charge and/or small size) are believed to be "structure makers", which globally enhance the H-bonded network. Large ions of low charge should act as "structure breakers", which destroy this network. ${ }^{92}$ In the biochemical literature the two types of ions are denoted as "kosmotropes" and "chaotropes, respectively. ${ }^{35,93}$ An optimum protein stabilization requires the combination of a chaotropic cation with a kosmotropic anion. ${ }^{35,93}$

Based on these ideas, there have been many discussions on how thermodynamic and kinetic properties of the underlying salt solutions themselves can be correlated with ion-specific effects on proteins. ${ }^{92,93}$ In particular, the so-called "viscosity B-coefficient", which describes the concentration dependence of the solution viscosity, ${ }^{94}$ is thought to be a reasonable predictor of Hofmeister effects. ${ }^{95,96}$ Such correlations have also been discussed at length for ILs, ${ }^{96}$ but have never been very precise Referring to the anion series quoted above, ${ }^{34}$ Ball ${ }^{90}$ has noted that the observations do not seem to fit into any ordering scheme that can be conveniently interpreted on the basis of putative chaotropic and kosmotropic hydration.

Recent experimental and theoretical work indeed suggests that the water structure is not central to the Hofmeister effect. ${ }^{16,89-91}$ On these grounds it has been suggested to dispose 
the kosmotrope/chaotrope concept at all. ${ }^{90}$ Instead, models are developed, which attribute Hofmeister effects to direct interactions of ions with macromolecule and their hydration water. ${ }^{16}$ Experiments exploiting the tunability of ILs may prospect valuable information on the role of potential contributions to the Hofmeister effects. In fact, the protein-destabilizing effects imposed by hydrophobic cations as well as anions point toward a key role of local hydrophobic forces.

\section{Effects of ionic liquids on non-native protein aggregation}

\section{Protein deactivation by non-native aggregation}

It has been long known ${ }^{97}$ that irreversible deactivation of proteins may be founded in non-native protein aggregation, which usually leads to precipitation of the protein. This is in contrast to the salting out of native protein above their solubility limit or the formation and precipitation of native oligomers. Non-native aggregation is not only critical at high temperatures, where proteins are unfolded, but also limits their long-time storage at ambient and physiological conditions. Obviously, the native ensemble comprises some fraction of aggregation-prone species far below $T_{\mathrm{m}}$. The avoidance of irreversible deactivation is a major challenge, ${ }^{8,15}$ which may, for example, enforce the formulation of proteins in lyophilized forms.

In the Lumry-Eyring scheme (1) unfolding is assumed to be reversible, while irreversibility is ascribed to non-native protein aggregation, ${ }^{7}$ and seems to occur in the early events associated with the formation of small oligomers. ${ }^{97}$ Solvent variation can affect any step in the sequence of unfolding and aggregation events, both thermodynamically and kinetically.

In the case of solutions of RNase A folding intermediates and aggregation have been addressed experimentally under various conditions. ${ }^{98-102}$ Dynamic light scattering, ${ }^{98}$ FT-IR spectroscopy ${ }^{99}$ and the separation of oligomers on gels ${ }^{100}$ show, for example, that RNase A readily forms small oligomers, which serve as nuclei for more complex structures. Conditions have been achieved where RNase A forms amyloid fibrils, ${ }^{101}$ although the propensity to do so is low.

Fig. 7 shows that ILs can stabilize RNase A against irreversible deactivation. The figure displays the time dependence of the deactivated fraction of RNase A molecules at $\mathrm{pH} 7.4$ after thermal incubation at $90{ }^{\circ} \mathrm{C} .{ }^{32}$ At this $\mathrm{pH}$ the protein is quite close to its isoelectric point ( $\mathrm{p} I=9.5)$, which, as discussed below, favours aggregation. The fraction of the deactivated protein was determined from the area under the unfolding peak in the DSC signal, which is proportional to the number of species participating in the unfolding equilibrium. After 30 minutes incubation of the IL-free solution the protein was almost completely deactivated. Addition of ILs, such as $\left[\mathrm{C}_{2} \mathrm{mim}\right][\mathrm{dca}]$, $\left[\mathrm{C}_{4} \mathrm{mim}\right] \mathrm{Br}$ and [chol][dhp], reduced the deactivation, albeit with different efficiency.

In parallel, we have analyzed the formation of oligomers by cathodic gel electrophoresis (SDS-PAGE), ${ }^{32}$ which identifies covalently linked aggregates. Incubation of the IL-free solution led to the formation of dimers, trimers and tetramers, and eventually resulted in a partial precipitation of the protein.

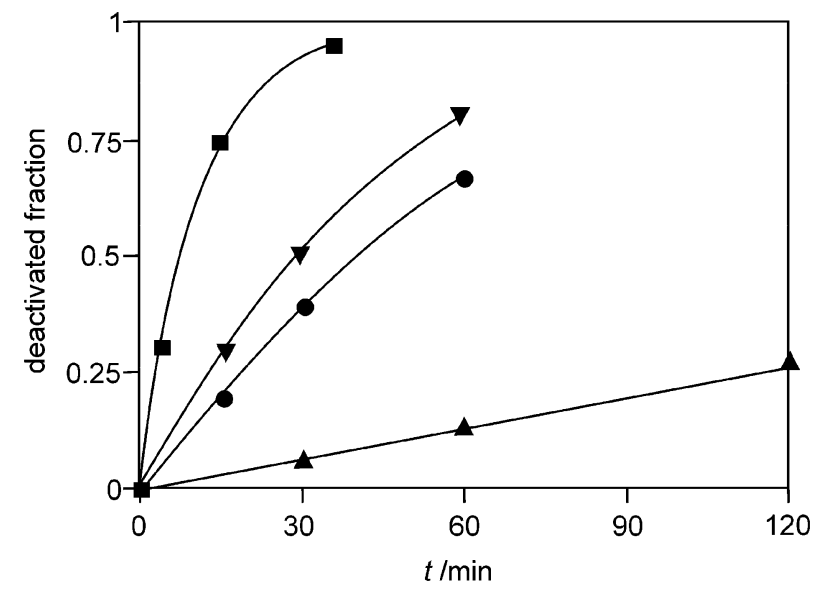

Fig. 7 Fraction of deactivated RNase A ( $20 \mathrm{mM}$ phosphate buffer, $\mathrm{pH}$ 7.4) as a function of the incubation time at $90{ }^{\circ} \mathrm{C}$. Squares: IL-free solution; circles: $1 \mathrm{M}$ [C $\mathrm{C}_{4}$-mim]Br; triangles down: $1 \mathrm{M}\left[\mathrm{C}_{2}\right.$-mim] $]$ dca]; triangles up: $1 \mathrm{M}$ [chol][dhp]. The estimated experimental accuracy of the denaturated fraction is $\pm 10 \%$.

By contrast, in solutions containing [chol][dhp] covalently bound oligomers could not be traced at all, and the monomer band retained its initial intensity during incubation. If [chol][dhp] was added after incubation, the oligomer bands were not suppressed. In other words [chol][dhp] was not able to redissociate irreversibly formed aggregates.

It is worthwhile to note that under strongly deactivating conditions the DSC profiles of RNase A solutions have revealed prepeaks due to some population of intermediates. ${ }^{31,32}$ It is not clear, whether these peaks reflect on-pathway species in the normal unfolding process or misfolds. As noted by Byrne and Angell, ${ }^{45,46}$ the right solvent environment, in their case created by highly concentrated hydrophilic ILs, stabilizes such conformations.

The limited number of experimental data renders general conclusions somewhat speculative, but taking together the relevant results ${ }^{31,32,45,46}$ the following picture is likely:

- For all ILs conditions, such as protein concentration, $\mathrm{pH}$, etc., can be found, at which they reduce the fraction of deactivated proteins, irrespective of their effect on the melting temperature $T_{\mathrm{m}}$.

- Addition of ILs affects irreversible deactivation already in the early stages of aggregation by hampering the formation of small oligomers.

- To suppress the formation of oligomers, ILs must be present during incubation. If added a posteriori, they will not do so.

- The possibility to use ILs for stabilizing non-native intermediates opens scenarios for mechanistic studies of protein unfolding/refolding.

\section{Conformational versus colloidal stability}

Noting the power of the Hofmeister series for describing ioninduced effects on the thermal and functional stability of native proteins, it is suggestive to explore the utility of this concept for non-native protein aggregation. For example, Yeh et al. have reported evidence for Hofmeister effects of inorganic ions on amyloid formation of a yeast prion protein, ${ }^{103}$ but there 
are counterexamples, where no correlations with Hofmeister rankings were found. ${ }^{104}$ In fact, there are no convincing arguments in favour of a general Hofmeister-type behaviour of protein aggregation because conformational changes and aggregation reflect different molecular interactions. In the former case the modification of intrapeptide interactions by the IL is the key factor. In the latter case modifications of intermolecular protein-protein interactions are crucial.

The role of protein-protein interactions for aggregation phenomena is well illustrated by $\mathrm{pH}$-induced effects. Often, proteins are stable against aggregation in some range of $\mathrm{pH}$ and become rapidly instable outside this range. ${ }^{8}$ These effects are usually founded in the electrostatic repulsion between the charged proteins, which disfavour aggregation energetically. Thus, irreversible aggregation is often very strong near the isoelectric point of the protein, where the positive or negative charge of the protein is low, while more distant from this point the protein's net charge can restore stability. ${ }^{8}$

Only if unfolding is the rate-determining step, one expects the Hofmeister behaviour. Stabilization of the native relative to the unfolded protein increases the Gibbs energy of unfolding $\Delta_{\text {unf }} G$, reducing the concentration of aggregation-prone species in the unfolding equilibrium. Additives which increase $T_{\mathrm{m}}$ should therefore hamper aggregation, whereas denaturating agents should enhance aggregation. In studies of ILs this correlation was not observed. ILs can hamper aggregation, irrespective of their effect on $T_{\mathrm{m}}{ }^{32,105}$ (see for example Fig. 7). A similar lack of an unambiguous correlation between $\Delta_{\mathrm{unf}} G$ and the efficiency of protein aggregation has been noted for uncharged co-solvents, such as saccharides, polyols or urea, and for [gua] $\mathrm{Cl}^{8}$

If irreversible protein aggregation is the key step in protein deactivation, the colloidal stability of the solution becomes the decisive property. The colloidal stability depends on the overall intermolecular forces between protein molecules. Avoidance of aggregation requires to stabilize the repulsive contributions of these forces. The colloidal stability of a solution can be characterized by the second osmotic virial coefficient, $B_{22}$. This quantity was originally defined with regard to the non-ideality of the osmotic pressure of a solution and is directly related to the overall intermolecular interactions between the protein molecules. ${ }^{106}$ Positive values of $B_{22}$ indicate the dominance of overall repulsive forces, whereas negative values reflect dominant attractive forces. To avoid aggregation $B_{22}$ should be positive.

The utility of $B_{22}$ for quantifying salt effects is well established in the field of protein crystallization, where crystallization is favoured within a "negative slot" of $B_{22}$ values. ${ }^{107}$ $B_{22}$ may therefore serve as a target for predicting the efficiency of salts for driving crystallization. The existing data base for salt effects on $B_{22}$ is, however, very limited and for ILs such data are essentially lacking.

The basic observations can be summarized as follows:

- The available experimental data exclude the existence of a general rule for predicting effects of ILs on protein aggregation because this process reflects conformational changes of the protein as well as the assembly of protein molecules to form aggregates.

- In the former case the conformational stability of the protein, as revealed by $\Delta_{\text {unf }} G$, is the decisive property. In the latter case the colloidal stability is relevant, which can be described by the second osmotic virial coefficient $B_{22}$ of the solution. Solution conditions that increase $B_{22}$ reduce aggregation, but there lacks any experimental information on effects of ILs on $B_{22}$, which would enable an understanding of the detailed molecular mechanism.

- The different nature of the conformational and colloidal processes renders a general Hofmeister-type approach for describing protein aggregation unlikely. This does not exclude that in specific cases the Hofmeister series will account for the observed effects. Moreover, it may be possible that the ion effects upon the colloidal stability themselves obey a Hofmeister-type ranking. ${ }^{35}$

\section{Conclusions}

ILs offer interesting features that can be exploited in biomolecular applications, such as biocatalysis or the formulation and storage of proteins. Their molecular-based understanding may avoid extensive preformulation studies for given applications.

On the phenomenological level the effects of ILs on the unfolding equilibrium are now experimentally well described and obey a Hofmeister series. In contrast to the widespread belief that Hofmeister effects can be well rationalized in terms of ion-induced changes of the bulk water structure, current interpretations focus on local ion-macromolecule-water interactions. The extension of the Hofmeister series to hydrophobic ions of ILs suggests a major role of salt-induced modifications of local hydrophobic interactions.

The molecular-based understanding of IL-induced effects on protein aggregation usually suffers from an incomplete knowledge of the colloidal stability at the given conditions. Despite some statements to the contrary, Hofmeister rankings do not seem to provide a general basis for assessing these salt effects on protein deactivation. It seems, however, that under carefully chosen conditions all ILs can stabilize proteins against aggregation, although they will do so with a different efficiency. Compared to other additives, the huge number of cations and anions that form ionic liquids allow fine-tuning of their solvent properties, which offers robust and efficient strategies for solvent optimization.

\section{Acknowledgements}

Dr Diana Constantinescu, Dr Adrian Syguda, Dr Yathrib Ajaj and Sebastian Weibels are thanked for helpful discussions and for preparing figures.

\section{Notes and references}

1 K. A. Dill, Biochemistry, 1990, 29, 7133.

2 A. D. Robertson and K. P. Murphy, Chem. Rev., 1997, 97, 1251.

3 J. Jonas and A. Jonas, Annu. Rev. Biophys. Biomol. Struct., 1994, 23, 287.

4 S. N. Timasheff, Proc. Natl. Acad. Sci. U. S. A., 2002, 99, 9721.

5 P. von Hippel and K.-Y. Wong, J. Biomol. Chem., 1965, 240, 3909.

6 S. Chan, S. Bromberg and K. A. Dill, Philos. Trans. R. Soc., B, 1995, 348, 61.

7 R. Lumry and H. Eyring, J. Phys. Chem., 1954, 58, 110.

8 E. Y. Chi, S. Krishnan, T. W. Randolph and J. F. Carpenter, Pharm. Res., 2003, 20, 1325.

9 C. M. Dobson, Nature, 2003, 426, 884. 
10 M. Vendruscolo and C. M. Dobson, Phil. Trans. R. Soc., A, 2005, 363, 433.

11 H.-C. Mahler, W. Friess, U. Grauschopf and S. Kiese, J. Pharm. Sci., 2009, 98, 2909.

12 C. Lange and R. Rudolph, in: Protein Folding Handbook, ed. T. Kiefhaber and J. Buchner, Wiley-VCH, Weinheim, Germany, 2005, pp. $1245-1280$.

13 A. Fersht, Structure and Mechanism in Protein Science, W. H. Freeman, New York, 1999.

14 P. Roach, D. Farrar and C. C. Perry, J. Am. Chem. Soc., 2005, 127, 8168 .

15 H. Hamada, T. Arakawa and K. Shiraki, Curr. Pharm. Biotechnol., 2009, 10, 400.

16 Y. Zhang and P. S. Cremer, Annu. Rev. Phys. Chem., 2010, 61, 63.

17 Ionic Liquids in Synthesis, ed. P. Wasserscheid and T. Welton, Wiley-VCH, Weinheim, 2nd edn, 2008.

18 Ionic Liquids: From Knowledge to Applications, ed. R. D. Rogers, N. V. Plechkova and K. R. Seddon, ACS Symposium Series, vol. 1030, 2009.

19 N. V. Plechkova and K. R. Seddon, Chem. Soc. Rev., 2008, 37, 123.

20 H. Weingärtner, Angew. Chem., Int. Ed., 2008, 47, 654.

21 H. Zhao, J. Chem. Technol. Biotechnol., 2010, 85, 891.

22 H. Zhao, J. Mol. Catal. B: Enzym., 2005, 37, 16.

23 P. van Rantwijk and R. Sheldon, Chem. Rev., 2007, 107, 2757.

24 Z. Yang, J. Biotechnol., 2009, 144, 12.

25 G. D. Elliott, R. Kemp and D. R. MacFarlane, in ref. 18, ch. 6, pp. 95-106.

26 R. M. Vrikkis, K. J. Fraser, K. Fujita, D. R. MacFarlane and G. D. Elliott, J. Biomech. Eng., 2009, 131, 0745141.

27 S. N. Baker, T. M. McCleskey, S. Panday and G. A. Baker, Chem. Commun., 2004, 940.

28 K. Fujita, D. R. MacFarlane and M. Forsyth, Chem. Commun., 2005, 4804.

29 N. Byrne, L.-M. Wang, J.-P. Belieres and C. A. Angell, Chem. Commun., 2007, 2714.

30 K. Fujita, D. R. MacFarlane, M. Forsyth, M. Yoshizawa-Fujita, N. Nakamura and H. Ohno, Biomacromolecules, 2007, 8, 2080.

31 D. Constantinescu, C. Herrmann and H. Weingärtner, in ref. 18, ch. 7 , pp. 107-117.

32 D. Constantinescu, C. Herrmann and H. Weingärtner, Phys. Chem. Chem. Phys., 2010, 12, 1756.

33 J. P. Mann, A. McCluskey and R. Atkin, Green Chem., 2009, 11, 785.

34 D. Constantinescu, C. Herrmann and H. Weingärtner, Angew. Chem., Int. Ed., 2007, 46, 8887.

35 K. D. Collins and M. W. Washabaugh, Q. Rev. Biophys., 1985, 18, 323.

36 W. Kunz, P. LoNostro and B. W. Ninham, Curr. Opin. Colloid Interface Sci., 2004, 9, 1.

37 P. G. Wolynes, J. N. Onuchi and D. Thirumalai, Science, 1995, 267, 1619.

38 R. B. Best and G. Hummer, Phys. Chem. Chem. Phys., 2011, 13, 16902 .

39 R. Janssen, W. Dzwolak and R. Winter, Biophys. J., 2005, 88, 1344.

40 D. R. Booth, M. Sunde, V. Bellotti, C. V. Robinson, W. L. Hutchinson, P. E. Frazer, P. N. Hawkins, C. M. Dobson, S. E. Radford, C. C. F. Blake and M. B. Pepys, Nature, 1997, $385,787$.

41 M. Bucciantini, E. Giannoni, F. Chiti, F. Baroni, L. Formigli, J. Zurdo, N. Taddel, G. Ramponi, C. M. Dobson and M. Stefani, Nature, 2002, 416, 507.

42 C. Lange, G. Patil and R. Rudolph, Protein Sci., 2005, 14, 2693.

43 R. Buchfink, A. Tischer, G. Patil, R. Rudolf and C. Lange, J. Biotechnol., 2010, 150, 64

44 M. L. Pusey, M. S. Paley, M. B. Turner and R. D. Rogers, Cryst. Growth Des., 2007, 7, 787.

45 N. Byrne and C. A. Angell, J. Mol. Biol., 2008, 278, 707.

46 N. Byrne and C. A. Angell, Chem. Commun., 2009, 1046.

47 F. Hofmeister, Arch. Exp. Pathol. Pharmakol., 1888, 64, 247.

48 K. D. Collins, Methods, 2004, 34, 300.

49 B. Hribar-Lee, K. A. Dill and V. Vlachy, J. Phys. Chem. B, 2010, 114(46), 15085.
50 P. B. Petersen and R. J. Saykally, Ann. Rev. Phys. Chem., 2006, 57, 333 .

51 N. Vlachi, B. Jagoda-Cwiklik, R. Vacha, D. Tourod, P. Jungwirth and W. Kunz, Adv. Colloid Interface Sci., 2009, 146, 42.

52 P. Lo Nostro, B. M. Ninham, A. Lo Nostro, G. Pesavento, L. Fratoni and P. Baglioni, Phys. Biol., 2005, 2, 1.

53 M. Riés-Kautt and A. F. Ducruix, J. Biol. Chem., 1989, 264, 745.

54 S. Finet, F. Skouri-Panet, M. Casselyn, F. Bonneté and A. Tardieu, Curr. Opin. Colloid Interface Sci., 2004, 9, 112.

55 K. Fumino, A. Wulf and R. Ludwig, Phys. Chem. Chem. Phys., 2009, 11, 8790.

56 T. L. Greaves and C. J. Drummond, Chem. Rev., 2008, 108, 206.

57 P. Walden, Bull. Acad. Imp. Sci. St.-Petersbourg, 1914, 8, 405.

58 K. Fumino, A. Wulf and R. Ludwig, Angew. Chem., Int. Ed., 2009, 48, 3184.

59 M. Krüger, S. Funkner, E. Bründermann, H. Weingärtner and M. Havenith, J. Chem. Phys., 2010, 132, 101101.

60 R. M. Vrikkis, K. J. Frazer, K. Fujita, D. R. MacFarlane and G. D. Elliott, J. Biomech. Eng., 2009, 131, 074514.

61 C. Reichardt, Solvents and Solvent Effects in Organic Chemistry, Wiley-VCH, Weinheim, Germany, 3rd edn, 2003.

62 M. Maroncelli, X.-X. Zhang, M. Liang, D. Roy and N. P. Ernsting, Faraday Discuss., 2012, DOI: 10.1039/C1FD00058F.

63 C. Wakai, A. Oleinikova, M. Ott and H. Weingärtner, J. Phys. Chem. B, 2005, 109, 17028.

64 M.-M. Huang, Y. Jiang, P. Sasisanker, G. J. Driver and H. Weingärtner, J. Chem. Eng. Data, 2011, 56, 1494.

65 H. Weingärtner, Z. Phys. Chem., 2006, 220, 1395.

66 M.-M. Huang and H. Weingärtner, ChemPhysChem, 2008, 9, 2172.

67 C. Reichardt, Green Chem., 2005, 7, 339.

68 R. Lungwitz, V. Strehmel and S. Spange, New J. Chem., 2010, 34, 1135 .

69 M. J. Kamlet, J. L. Abboud and R. W. Taft, J. Am. Chem. Soc., 1977, 99, 8325

70 J. P. Hallet and T. Welton, ECS Trans., 2009, 16, 33.

71 S. Park and R. J. Kazlauskas, J. Org. Chem., 2001, 66, 8395.

72 J. Mutschler, T. Rausis, J.-M. Bourgeois, C. Bastian, D. Zufferey and I. V. Mohrenz, Green Chem., 2009, 11, 1793.

73 D. Chandler, Nature, 2005, 437, 640.

74 P. J. Halling, Enzyme Microb. Technol., 1994, 19, 178.

75 H. Weingärtner, T. Merkel, U. Maurer, J.-P. Conzen, H. Glasbrenner and S. Käshammer, Ber. Bunsenges. Phys. Chem., 1991, 95, 1579.

76 A. Triolo, O. Russina, H.-J. Bleif and E. di Cola, J. Phys. Chem. B, 2007, 111, 4641.

77 J. N. A. Canongia Lopes and A. A. H. Padua, J. Phys. Chem. B, $2006,110,3330$.

78 H. Zhao, G. A. Baker, Z. Song, O. Olubajo, T. Crittle and D. Peters, Green Chem., 2008, 10, 696.

79 A. M. Klibanov, CHEMTECH, 1986, 16, 354.

80 A. Sheldon, G. Stephens and K. R. Seddon, Green Chem., 2004, 6, G65-G66.

81 A. Sheldon, Chem. Commun., 2001, 2399.

82 D. Sate, M. H. A. Janssen, G. Stephens, R. A. Sheldon, K. R. Seddon and J. R. Lu, Green Chem., 2007, 9, 859.

83 Y. Ajaj, PhD thesis, Ruhr-University Bochum, Germany, 2010.

84 H. Bisswanger, Practical Enzymology, Wiley-VCH, Weinheim, 2004.

85 H. Weingärtner, A. Syguda, C. Herrmann and S. Weibels, unpublished data.

86 B. M. Bulheller, A. Rodger and J. D. Hirst, Phys. Chem. Chem. Phys., 2007, 9, 2020.

87 S. M. Kelly and M. C. Price, Biochim. Biophys. Acta, 1997, 1338, 161.

88 C. Cabrele, to be published.

89 P. Ball, Chem. Rev., 2008, 108, 74.

90 P. Ball, ChemPhys Chem, 2008, 9, 2677.

91 D. J. Tobias and J. C. Hemminger, Science, 2008, 319, 1197.

92 Y. Marcus, Chem. Rev., 2009, 109, 1346.

93 R. L. Baldwin, Biophys. J., 1996, 71, 2056.

94 R. H. Robinson and R. A. Stokes, Electrolyte Solutions, Butterworths, London, 2nd edn, 1969.

95 J. M. Broering and A. S. Bommarius, J. Phys. Chem. B, 2005, 109, 20612. 
96 H. Zhao, J. Chem. Technol. Biotechnol., 2006, 81, 877.

97 L. R. Deyoung, A. L. Fink and K. A. Dill, Acc. Chem. Res., 1993, 26, 614.

98 A. M. Tsai, J. H. van Zanten and M. J. Betenbaugh, Biotechnol. Bioeng., 1998, 59, 273; A. M. Tsai, J. H. van Zanten and M. J. Betenbaugh, Biotechnol. Bioeng., 1998, 59, 281.

99 Y.-B. Yan, J. Zhang, H.-W. Hei and H.-M. Zhou, Biophys. J., 2006, 90, 2525.

100 G. Gotte, F. Voratiello and M. Libonati, J. Biol. Chem., 2003, 278, 1076375.

101 S. D. Stelea, P. Pancoska, A. S. Benight and T. A. Keiderling, Protein Sci., 2001, 10, 970.
102 Y. Liu, G. Gotte, M. Libonati and D. Eisenberg, Nat. Struct. Biol., 2001, 8, 211.

103 V. Yeh, J. M. Broering, A. Romanyuk, B. Chen, Y. O. Chernoff and A. S. Bommarius, Protein Sci., 2010, 19, 47.

104 H. R. Kalhor, M. Kamizi, J. Akbari and A. Heydari, Biomacromolecules, 2009, 10, 2468.

105 C. A. Summers and R. A. Flowers II, Protein Sci., 2000, 9, 2001.

106 See e.g. R. A. Curtiss, H. W. Blanch and J. M. Prausnitz, J. Phys. Chem. B, 2001, 105, 2445.

107 A. George and W. W. Wilson, Acta Crystallogr., Sect. D: Biol. Crystallogr., 1994, 50, 361. 